\title{
Free radical scavenging activity of taro (Colocasia esculenta (L.) Schott) varieties with varying flesh color
}

\author{
Erlinda A. Vasquez, Precila D. Contero and Dilberto 0. Ferraren
}

\begin{abstract}
Submitted: 22 February 2019 | Accepted: 24 March 2020

Corms of five taro varieties namely: two NSIC-registered varieties, VG-1 (Kalpao) and VG-2 (Iniito), and three farmer's variety, PRG 322 (Chowking), PRG 381 (Pandaga), and PRG 380 (Salot), were evaluated for antioxidant activity using 1, 1diphenyl-2 picrylhydrazyl (DPPH) assay before and after cooking. The purplefleshed varieties PRG 322, PRG 380 and VG-2 showed higher antioxidant activity than the yellow- and cream-fleshed varieties, The monomeric anthocyanin contents of PRG 380 and VG-1 PRG 322 and VG-2, which showed the highest free radical scavenging activity were measured using the $\mathrm{pH}$ differential method. The freeradical scavenging activity of the five taro varieties ranged from 134 to $154 \mathrm{TE} \mu \mathrm{m} \mathrm{g}^{-1}$ when raw and 127 to $147 \mathrm{TE} \mu \mathrm{m} \mathrm{g}^{-1}$ when cooked with the highest activity in raw PRG 322 followed by raw PRG 380 and VG-2. Cooked PRG 381 and VG-1 showed the lowest activity. Cooking reduced the activity by $4.5-10.2 \%$ with PRG 380 showing the highest reduction rate while the other four varieties did not vary significantly from 4.5-5.9\%. Decreased in antioxidant activity can be due to the degradation and leaching out of antioxidant compounds during steamed cooking.
\end{abstract}

Keywords: taro, DPPH assay, anthocyanin, antioxidant, free radicals

\section{INTRODUCTION}

Growing body of research suggests that the most common health problems are heart disease, macular degeneration, cancer, cardiovascular diseases (Gerber et al 2001), diabetes, Alzheimer's disease, Parkinson's disease (Di Matteo \& Esposito 2003), and many other illnesses that are perhaps associated with aging itself. It includes a common link: a class of molecules known as "free radicals". These are highly unstable molecules that are naturally formed when the body converts food

Philippine Root Crops Research and Training Center (PhilRootcrops), Visayas State University, Baybay City, Leyte 6521-Philippines

*Corresponding Author. Address: Philippine Root Crops Research and Training Center (PhilRootcrops) Visayas State University, Baybay City, Leyte 6521-Philippines; Email: ditchie47@gmail.com DOI: $10.32945 /$ atr4212.2020 
into energy. Free radicals can cause "oxidative stress," a process that can trigger cell damage (Goodman et al 2011).

Free radical scanvengers such as antioxidants are substances or nutrients in the foods which prevent or slow down the oxidative damage in the body (Halliwell \& Gutteridge JMC 1999 \& 2015, Sanchez-Moreno 2002). Antioxidants include the nutrient antioxidants, vitamins $\mathrm{A}, \mathrm{C}$ and $\mathrm{E}$, and the minerals copper, zinc and selenium (Ronzio 2013). Most of the antioxidants in a typical diet are plant-based belonging to different classes of compounds especially the phenols and polyphenols (Prakash et al 2011, Prakash et al 2001).

One of the food sources that can provide free-radical scavenging properties is taro (Colocasia esculenta (L.) Schott) which is locally known as "gabi" or "eddo, dasheen, cocoyam, colocasia, elephant's ear, kalo", etc. Its underground root, the corm, is one of the popular edible root vegetables in large parts of Asia including the Philippines. It is also one of the finest sources of dietary fibers, with excellent content of potassium, calcium, vitamins $\mathrm{C}, \mathrm{E}$ and $\mathrm{B}$, as well as magnesium, manganese, and copper. Taro corm contains higher nutritional value than potato, sweet potato, cassava and rice. It has almost three times the dietary fiber, which is important for proper digestive health and regularity. It has a low glycemic index (GI), compared to potato. A low GI means that it effects blood sugar levels slowly, without the peaks and crashes of a high GI. A low GI food also help prevent diabetes. Taro leaves contain good amount of vitamins $A$ and $C$, fiber, and a relatively high amount of protein. The flesh varies from white, cream yellow color to violet depending on cultivar types. Hence, this study was conducted to evaluate the free radical scavenging activity of selected five taro varieties with varying flesh colors as basis for the promotion of its nutraceutical benefits.

Some taro varieties contain phenolics (eg, anthocyanins, flavonols or flavanols) and carotenoids like $\beta$-carotene (Champagne et al 2010, 2011). Phenolics are used to decrease asthma symptoms caused by exercise, to prevent certain cancers, heart disease, cataracts, and age related macular degeneration. Evidence suggests that phenolic compounds consumption may protect from some disorders including cancers (Ding et al 2006) cardiovascular diseases (Bell \& Gochenaur 2006), age-related neurodegenerative declines (Lau et al 2006) and some other endothelial and mitochondrial dysfunctions (Soto-Vaca et al 2012).

The study aimed to evaluate the free radical scavenging activity of taro with varying flesh colors before and after cooking and to determine the monomeric anthocyanin in two varieties with highest antioxidant property.

\section{MATERIALS AND METHODS}

\section{A. Planting and Collection of Taro Varieties}

The five taro varieties namely: 2 NSIC registered varieties, VG-1 (Kalpao) and VG-2 (Iniito), and the three farmer's varieties, PRG 322 (Chowking), PRG 380 (Salot) and PRG 381 (Pandaga) were planted at the Calbigaa experimental area, PhilRootcrops, Visayas State University, Visca, Baybay, City Leyte. 
Free radical scavenging activity of taro

The established crops were maintained following the standard taro production practices. The corms used for the assay were harvested after eight months from planting.

\section{B. Preparation of Sample for the Assay}

The corms of the five taro varieties (Figure 1) were thoroughly washed with running tap water to rinse the dirt particles that adhere to the plant materials and was drained to remove excess water. They were manually peeled and cut into small pieces. One section was retained as raw and the others were steamed/cooked in a water bath at $90^{\circ} \mathrm{C}$ for three hours.

A.
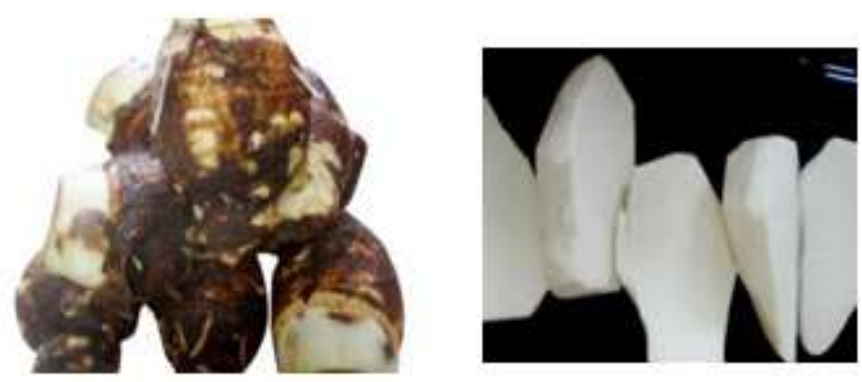

B.
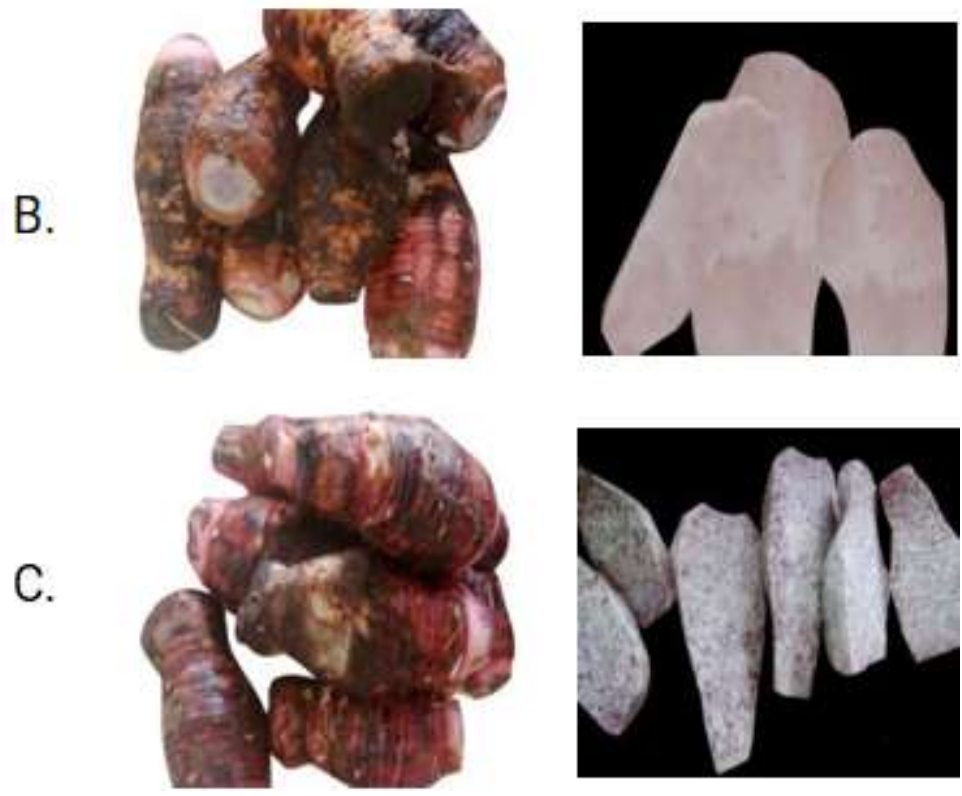

Figure 1.Taro varieties with varying corm flesh colors: A. VG-1 (Kalpao)-cream, B. VG-2 (Iniito)-light pink with scattered purple streaks, CPRG 322 (Chowking)pink with dense purple streaks, D. PRG 381 (Pandaga)-yellow orange, and E. PRG 380 (Salot) -white with uniform purple streaks 

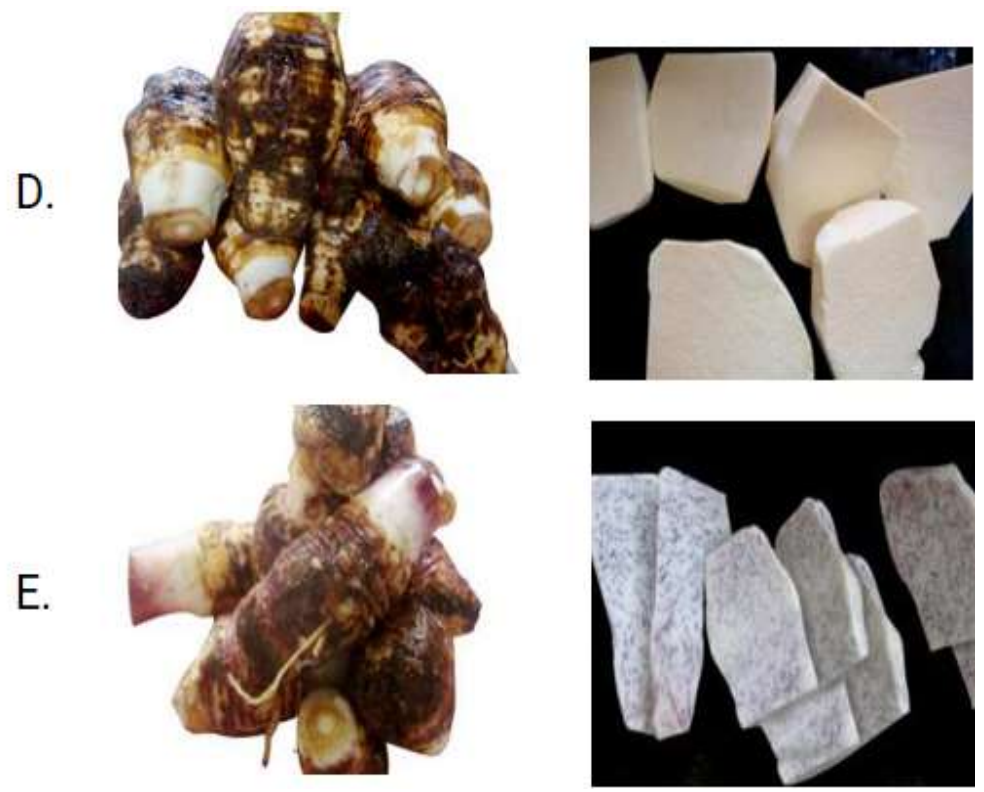

Figure 1. continued

\section{Chemicals and Reagents}

Analytical grades of the following reagents purchased from Sigma-Aldrich company were used: Trolox (6-hydroxy-2, 5, 7, 8-tetramethyl-chroman-2-carboxylic acid) and DPPH (1, 1-diphenyl-2 picrylhydrazyl), potassium chloride, sodium acetate, ethanol and hydrochloric acid.

\section{Extraction of Anthocyanin Pigments from Taro Corm}

Ten grams of uncooked and steamed cooked taro corms that were cut into small pieces were placed in separate blenders with $20 \mathrm{~mL}$ solution of $1 \%$ hydrochloric acid $(\mathrm{HCl})$ in ethanol and homogenized. The macerates were transferred in a beaker covered with parafilm and wrapped with a carbon paper to minimize the degradation of pigments before storing overnight in the refrigerator.

The refrigerated samples were filtered and the filtrate was centrifuged at $2500 \mathrm{rpm}$ for $20 \mathrm{~min}$. The supernatant was transferred to a $100 \mathrm{~mL}$ volumetric flask and diluted with the extracting solvent of $1 \% \mathrm{HCL}$ in ethanol.

\section{E. Free Radical Scavenging Activity of Taro Corm Extracts}

The antioxidant activity of all extracts and fractions was determined following the standard protocol of Brand-Williams et al (1995) with some modifications. The stock solution of DPPH (30 $\left.\mathrm{mg} \mathrm{L}^{-1}\right)$ was prepared using ethanol/water solvent. Initial absorbance was determined using UV-Vis Spectrophotometer (Shimadzu UV$1800)$ at $517 \mathrm{~nm}$. Aliquots of the sample were diluted with ethanol and was pipetted into a $3.9 \mathrm{~mL}$ of DPPH solution to initiate the reaction. The solution was thoroughly 
Free radical scavenging activity of taro

mixed and allowed to stand at an ambient temperature in the dark for three hours to give enough time for the reaction of the cellular antioxidants with DPPH. Absorbance of the extracts were measured at the established $\kappa_{\max }$. Trolox of different concentrations $(0,100,200,300,400 \& 500 \mu \mathrm{M})$ were used as reference standards.

The quantity of each sample necessary to react with one-half of the DPPH solution was expressed in terms of the micromole equivalents of the Trolox (TE) per gram fresh weight of the sample or Trolox units per gram. Analyses were done in triplicate.

\section{F. Analysis of the Total Monomeric Anthocyanin by pH-Differential Method (Giusti \& Wrolstad 2001)}

Of the three purple-colored taro varieties, only two, VG-2 and PRG 322, were selected for the free radical assay of corms because of the limited number of corm produced by PRG 381 which was planted under upland condition when in fact it should have been planted at lowland condition.

Each sample taken from the taro corms was diluted with two different solutions, one with $0.025 \mathrm{M} \mathrm{KCl}$ buffer with $\mathrm{pH} 1$ while the other, with $0.4 \mathrm{M}$ sodium acetate $(\mathrm{NaOAc})$ buffer with a $\mathrm{pH}$ of 4.5 . Concentrated $\mathrm{HCl}$ was used to check and adjust each buffer before using. Nine $\mathrm{mL} \mathrm{KCl}$ buffer was added to one of the test tubes and $9 \mathrm{~mL} \mathrm{NaOAc}$ buffer to the other test tube.

The absorbance of each dilution was measured at its $K_{\text {vis-max }}$ against a blank cell with distilled water. Its absorbance and concentration of monomeric anthocyanin was calculated using the equation:

A. Absorbance

$$
\mathrm{A}=\left(\mathrm{A} \widehat{K}_{\text {vis-max }}-\mathrm{A}_{700 \mathrm{~nm}}\right)_{\mathrm{pH} 1.0}-\left(\mathrm{A} \kappa_{\text {vis-max }} \mathrm{A}_{700 \mathrm{~nm}}\right)_{\mathrm{pH} 4.5}
$$

B. Concentration of monomeric anthocyanin

$$
\operatorname{Macy}\left(\mathrm{mgL}^{-1}\right)=(\mathrm{A} \times \mathrm{MW} \times \mathrm{DF} \times 1000) /(\varepsilon \times 1)
$$

Where:

$$
\begin{aligned}
& \text { A - absorbance } \\
& \text { MW - molecular weight of the predominant pigment component } \\
& \text { DF - dilution factor } \\
& \mathcal{E} \quad \text { - Molar absorptivity }
\end{aligned}
$$

\section{Statistical Analysis}

The experiment was laid out using 2-factor factorial in Completely Randomized Design (CRD) with three replications. Factors that showed significant difference in the Analysis of Variance (ANOVA) were further analyzed using the Tukey's Honestly Significance Difference (HSD) Test. 


\section{RESULTS AND DISCUSSION}

\section{Free Radical Scavenging Activity of Taro Varieties}

The free radical scavenging activity of the five taro varieties, namely: VG-1, VG2 and the farmer's varieties -PRG 322, PRG 381 and PRG 380 with different flesh colors evaluated using the ethanolic solution of the stable free radical known as DPPH (1,1-diphenyl-2-picrylhydrazyl) is presented in Table 1. DPPH is widely used to test the ability of compounds to act as free radical scavengers or hydrogen donors and during assay of antioxidant activity of foods. It has also been used to quantify antioxidants in complex biological systems in recent years. Trolox was used as standard in the DPPH assay and the standard line generated has a regression of 0.994 .

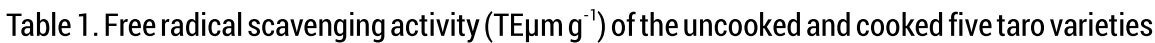

\begin{tabular}{lccc}
\hline \multirow{2}{*}{ Variety } & \multicolumn{2}{c}{ Treatment } & \multirow{2}{*}{$\%$ Reduction } \\
\cline { 2 - 3 } & Uncooked & Cooked & \\
\hline VG-1 (Kalpao) & $134.24 \mathrm{~d}$ & $127.23 \mathrm{c}$ & $5.21 \mathrm{~b}$ \\
VG-2 (Iniito) & $143.55 \mathrm{c}$ & $135.96 \mathrm{~b}$ & $5.86 \mathrm{~b}$ \\
PRG 322 (Chowking) & $153.62 \mathrm{a}$ & $146.60 \mathrm{a}$ & $4.52 \mathrm{~b}$ \\
PRG 381 (Pandaga) & $135.78 \mathrm{~d}$ & $128.25 \mathrm{c}$ & $5.54 \mathrm{~b}$ \\
PRG 380 (Salot) & $148.86 \mathrm{~b}$ & $134.47 \mathrm{~b}$ & $10.17 \mathrm{a}$ \\
\hline
\end{tabular}

Values with the same letters are comparable at $a=0.05$, Tukey HSD

It has been a scientifically-proven fact that the darker the food such as those with purple pigments, the higher the antioxidant level. In this study the purplefleshed varieties - PRG 322, PRG 380 and VG-2 showed significantly higher antioxidant activity than the yellow-and cream-fleshed varieties, PRG 381 and VG-1 variety, respectively (Table 2 ).

Using the Trolox standard, the free-radical scavenging activity of the five taro varieties ranged from 134-154TE $\mu \mathrm{m} \mathrm{g}^{-1}$ when raw and 127-147TE $\mu \mathrm{m} \mathrm{g}^{-1}$ when cooked with the highest activity in PRG 322 and followed by PRG 380 and VG-2, all of which are purple-fleshed. Both PRG 381 and VG-1 had the lowest activity but no significant difference in both treatments. It is also observed that cooking reduced the activity by $4.5-10.2 \%$ with PRG 380 showing the highest reduction rate while the other four varieties did not vary significantly from $4.5-5.9 \%$. The decreased in the total antioxidant activity may also be due to the leaching out of the water soluble antioxidants during the cooking process. The results indicate that the antioxidant compound in PRG 381 may not be thermally stable Similar study on the antioxidant activity of taro corm was evaluated on raw methanolic extract only (Yadav et al 2017). The antioxidant activity obtained was relatively lower than the findings in this study. The difference could be in the solvent for extraction and the taro variety used. Antioxidant compounds can be water-soluble, insoluble, lipid-soluble or bound to the cell walls, thus extraction process is crucial in quantification of antioxidant activity for food (Prakash et al 2001) The taro corm extract had higher activity than Vitamin $\mathrm{C}$ which could be associated with considerable amount of phenolics and flavonoids as water-soluble antioxidants. 
Free radical scavenging activity of taro

It is known that heat can destroy the quality of food attributes, such as color, texture, nutrients and phytochemicals that are beneficial to health. The natural antioxidants contained in foods can be lost to a significant degree during processing like boiling, drying or handling such as peeling and slicing, as well as during storage. These bioactive compounds are relatively unstable when subjected to heat. Cooking often reduces the total antioxidant activity of foods, but in some cases, these levels are increased in cooked foods (Wu et al 2004, Choi 2006). The increased antioxidant activity with heat treatment could be attributed to the deactivation of endegenous oxidative enzyme which prevent further oxidation in the antioxidant Compounds in raw materials (Nicoli et al 1999, Dewantu et al 2002).

It is often claimed that antioxidant activities generally increase with color. In this study, cooking intensified the color of taro flesh as seen in the more intense color of the extract from cooked taro than from the raw ones (Figures 2 ). The result however contradicted such claim with the reduction in the free radical scavenging activity after cooking (Table 1). This means that it is not the intensity of colors that govern the free radical scavenging activity as observed in this study but the content of the antioxidant compound present in the substrate.

UNCOOKED

VG-1 (Kalpao)

VG-2 (Iniito)

PRG 322 (Chowking)
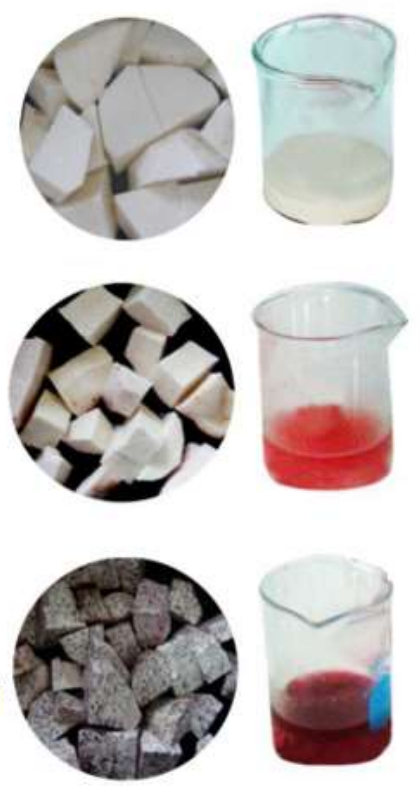
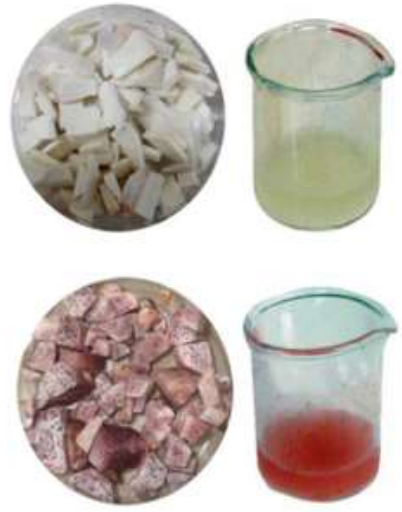

COOKED
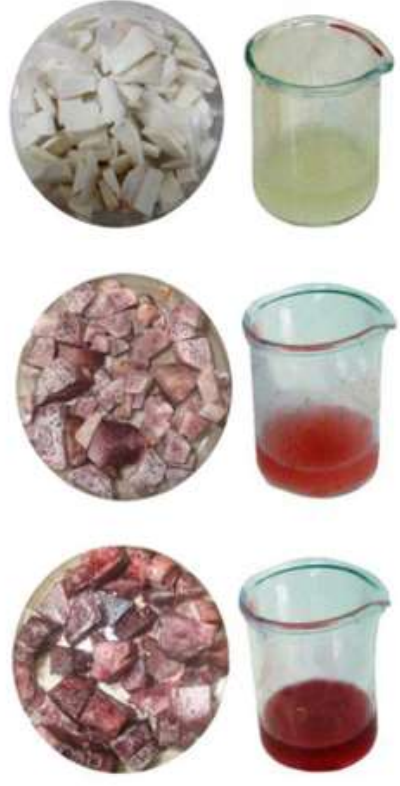

Figure 2. Taro corm appearance and extracts before and after cooking 

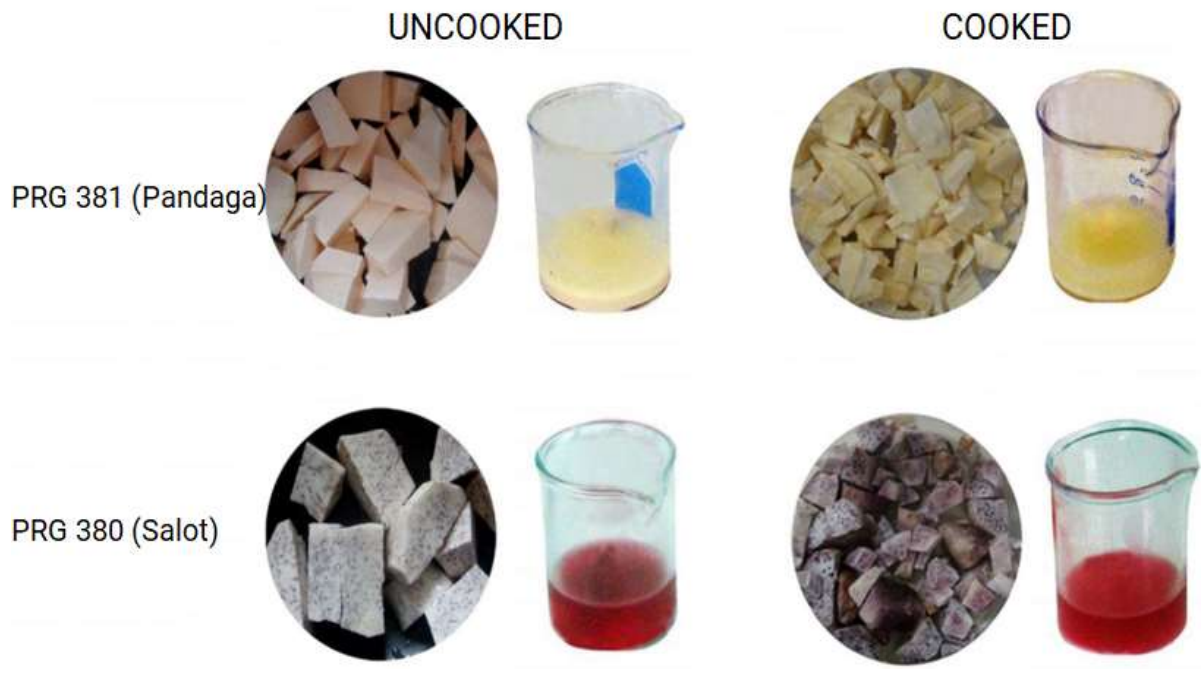

Figure 2. continued

\section{Anthocyanin Pigments from Two Taro Varieties with High Free Radical Scavenging Activity}

Extraction is a fundamental technique used to isolate a compound from a mixture. It generally involves the use of acidic solvents, which denatures the membranes of cell tissue and simultaneously dissolved the pigments.

The wide range of color in raw and cooked taro corm extracts determines the approximate comparison of the amount of anthocyanin present in cooked and uncooked taro varieties. Total monomeric anthocyanin by $\mathrm{pH}$-differential method of Giusti \& Wrolstad (2001) was used to determine the total anthocyanin present in two taro varieties with high free radical scavenging activities The molecular weight and molar absorptivity of anthocyanidin-3 glucoside were used in the computation for the total monomeric anthocyanin. It was suggested that if the identity of the pigment is unknown the concentration can be expressed as cyanidine-3-glucoside since it is the most abundant in nature.

PRG 322 has inherently higher anthocyanin content than VG-2 (Table 2) as further supported by color intensity in the corm flesh and ethanolic extract (Figure $3)$. The concentration of anthocyanin in raw taro was higher than in cooked taro. Cooking reduced the anthocyanin content up to $91 \%$. This high loss can be explained by the water solubility of anthocyanin which possibly leached out during steamed cooking.

The higher oxidant activity of PRG 322 than VG-2 (Table 2) can be associated with the high anthocyanin content of the former than the latter before cooking and the residual amount after cooking. PRG 322 therefore is a good candidate variety as a staple food with its antioxidant property. Besides, this is also a high yielding and low acridity farmer's variety. 
Free radical scavenging activity of taro

Table 2. Monomeric anthocyanin content in uncooked and cooked taro corms.

\begin{tabular}{lccc}
\multicolumn{1}{c}{ Variety } & Uncooked & Cooked & \% Reduction \\
\hline PRG 322 (Chowking) & $78.26 \mathrm{a}$ & $7.013 \mathrm{a}$ & 91.04 \\
VG-2 (Iniito) & $5.789 \mathrm{~b}$ & $0.645 \mathrm{~b}$ & 88.85 \\
\hline
\end{tabular}

Means in the row followed by the same letters are not significantly different using t-test at $1 \%$ level.

\section{CONCLUSIONS}

PRG 322 had the highest free radical scavenging activity among the taro varieties evaluated followed by PRG 380 and VG-2. PRG 380 had significantly higher activity than VG-2 when uncooked but, this two exhibited a comparable results when cooked. The yellow flesh variety PRG 381 and the cream variety VG-1 had the lowest antioxidant activity both in cooked and uncooked condition. The antioxidant activity in taro is associated with anthocyanin present in the purple flesh varieties. From the results of the total monomeric anthocyanin assay by $\mathrm{pH}$-differential method, PRG 322 had higher anthocyanin content than VG-2. Even if there was 88$91.04 \%$ anthocyanin reduction when cooked, PRG 322 still contained higher amount than VG-2 since it had seven times more anthocyanin in flesh corm than the latter.

\section{REFERENCES}

Bell DR and Gochenaur K. 2006. Direct vasoactive and vasoprotective properties of anthocyanin rich extracts. Journal of Applied Physiology 100(4):1164-1170

Brand-Williams W, Cuvelier ME \& Berset C. 1995. Use of a free radical method to evaluate antioxidant activity. Lebensmittel Wissenschaft Technologie-Food Science and Technology 28:25-30

Champagne A, Hilbert G, Legendre L \& Lebot V. 2011. Diversity of anthocyanins and other phenolic compounds among tropical root crops from Vanuatu, South Pacific. Journal of Food Compilation Analysis 24(3):315-325

Champagne A, Bernillon S, Moing A, Rolin D, Legendre L \& Lebot V. 2010. Carotenoid profiling of tropical root crop chemotypes from Vanuatu, South Pacific. Journal of Food Compilation Analysis 23(8):763-771

Choi YM, Lee SM, Chun J, Lee HB \& Lee J. 2006. Influence of heat treatment on the antioxidant activities and polyphenolic compounds of Shiitake (Lentinus edodes) mushroom. Food Chemistry 99(2):381-387

Dewanto V, Wu X, Adam KK \& Liu RH. 2002. Thermal processing enhances the nutritional value of tomatoes by increasing total antioxidant activity. Journal of Agricultural and Food Chemistry 50:3010-3014

Di Matteo $V$ and Esposito E. 2003. Biochemical and therapeutic effects of antioxidants in the treatment of Alzheimer's disease, Parkinson's disease, and amyotrophic lateral sclerosis. Current Drug Target CNS and Neurological Disorder 2(2):95-107

Ding M, Feng R, Wang SY, Bowman L, Lu Y, Qian Y, Castranova V, Jiang BH \& Shi X. 2006. Cyanidin-3-glucoside, a natural product derived from blackberry, exhibits chemopreventive and chemotherapeutic activity. The Journal of Biological Chemistry 281(25):17359-17368 
Gerber M, Boutron-Ruault MC, Hercberg S, Riboli E, Scalbert A \& Siess MH. 2001. Food and cancer: state of the art about the protective effect of fruits and vegetables. Bulletin du cancer 89(3):293-312

Goodman M, Bostick RM \& Kucuk O. 2011. Clinical trials of antioxidants as cancer prevention agents: past, present, and future. Free Radical Biology \& Medicine 51(5):1068-1084

Guist M and Wrolstad RE. 2001. Characterization and measurement of anthocyanin by UV-Spectroscopy. Current Protocols in Food Analytical Chemistry F.2.1F1.2.13

Halliwell B and Gutteridge JMC. 1999. Free Radicals in Biology and Medicine (3rd edn). Oxford University Press, New York, USA

Halliwell B and Gutteridge JMC. 2015. Free Radicals in Biology and Medicine (5th edn). Oxford University Press, New York, USA

Lau FC, Shukitt-Hale B \& Joseph JA. 2006. Beneficial effects of berry fruit polyphenols on neuronal and behavioral aging. Journal of the Science of Food and Agriculture 86(14):2251-2255

Nicoli MC, Anese M, Parpinel MT \& Francheschi S. 1999. Influence of processing on the antioxidant properties of fruits and vegetables. Trend in Food Science and Technology 10(3):94-100

Prakash D, Upadhyay G, Pushpangadan P \& Gupta C. 2011. Antioxidant and free radical scavenging activities of some fruits. Journal of Complementary and Integrative Medicine 8(1):1-16

Prakash A, Rigelhof F \& Miller E. 2001. Antioxidant Activity. Medallion Laboratories Analytical Progress 19(2):1-4

Ronzio RA. 2013. Naturally occurring antioxidants. In JE Pizzorno and MT Murray (eds) Textbook of Natural Medicine (4th edn) (pp891-914). St. Louis: Elsevier

Sanchez-Moreno C. 2002. Review: Methods used to evaluate the free radical scavenging activity in foods and biological systems. Food Science and Technology International 8(3):121-137

Soto-Vaca A, Gutierrez A, Losso JN, Xu Z \& Finley JW. 2012. Evolution of phenolic compounds from color and flavor problems to health benefits. Journal of Agricultural and Food Chemistry 60(27):6658-6677

Valko M, Rhodes CJ, Moncol J \& Izakovic M. 2006. Free radicals, metals and antioxidants in oxidative stress-induced cancer. Mini-review. Chemicobiological interactions 160(1):1-40

Wu X, Beecher GR, Holden JM, Haytowitz DB, Gebhardt SE \& Prior RL. 2004. Lipophilic and hydrophilic antioxidant capacities of common foods in the United States. Journal of Agricultural and Food Chemistry 52(12):4026-4037

Yadav M, Kushawaha DK, Chatterji S \& Watal G. 2017. Assessment of antioxidant activity and phytochemical screening of Colocasia esculenta corm. International Journal of Pharmaceutical Sciences and Research 8(4):17581764 